\title{
Slow Orthodontic Teeth Extrusion to Enhance Hard and Soft Periodontal Tissue Quality before Implant Positioning in Aesthetic Area
}

\author{
Maiorana C. ${ }^{1}$, Speroni S. ${ }^{1}$, Herford A.S. ${ }^{2}$ and Cicciù M. ${ }^{3, *}$ \\ ${ }^{I}$ Oral Surgery and Implantology, University of Milan School of Dentistry, University of Milan, MI, Italy \\ ${ }^{2}$ Department of Oral \& Maxillofacial Surgery, Loma Linda University, Loma Linda, CA, USA \\ ${ }^{3}$ Department Of Human Pathology, Via Consolare Valeria 98100, Messina
}

\begin{abstract}
Approaching bone defects of jaws treatments, hard and soft tissue augmentation could be considered as a goal for clinicians when performing dental implant placement. The increase in patients who want cosmetic treatment puts practitioners in an awkward position when choosing the best therapy to obtain the most desirable results.

A private dentist referred a young patient to the Department of Implantology in Milan in order to place implants in the upper jaw. Radiographic evaluation of the two upper anterior incisors confirmed that the teeth had a poor prognosis The anterior ridge volume was clinically analyzed and several therapeutic choices were evaluated. Rapid extractions and immediate implant positioning were not considered due to the vertical and horizontal components of the bone defect. Therefore, the surgical team decided on increasing the bone volume by using slow orthodontic teeth extrusion technique.

After 3 months of orthodontic treatment, the angular intra-bony defects of 1.1 tooth was completely healed. Implant guided positioning, associated with a small bone graft, showed optimal results at the time of healing screw placement. The soft tissue conditioning was obtained by a provisional acrylic crown. The final application of two integral ceramic crowns showed excellent aesthetic results. Radiographic investigation at a 24 month follow-up confirmed the integration of the dental implants and the recovery of the bone defects.

Several safe surgical techniques are available today for reconstructing atrophic jaws. However, the same technique applied on the posterior area did not give the same predictable results as in the anterior areas of the jaw.
\end{abstract}

Keywords: Orthodontic extrusion, teeth extraction, periodontal tissues, dental implants.

\section{INTRODUCTION}

The progressive resorption of the alveolar bone begins following tooth loss and is accompanied by a reduction in both the quality and quantity of hard and soft tissues.

The healing events occurring after tooth extraction need to be understood for a complete evaluation of the appropriate time for implant positioning [1]. It was shown that after extracting a natural tooth, the greatest reduction of the alveolar bone occurs in the first 6 months to 2 years [2-4]. An estimate of $25 \%$ decrease in buccopalatal width occurs within the first year [4-8]. For this reason, in the last few decades, the 'gold standard' implant treatment protocol has been challenged by experiments whose aim is to shorten the treatment period and reduce the number of surgical procedures. Literature has demonstrated that it is no longer necessary to wait for complete healing of the extraction socket before implant placement [9-12].

Surgical diagnosis and analysis before starting the implant therapy is gaining great significance, in particular in

*Address correspondence to this author at the Oral Surgery, Department of Human Pathology Via Commenda ${ }^{\circ} 10$, 20122, Milano, Italy;

Tel/Fax: 0039-0902216920; E-mail: acromarco@yahoo.it the area of aesthetics. The achievement of a correct architecture of soft tissues and respect for aesthetic values should be considered in order to achieve a gratifying clinical result for both the patient and the surgeon.

Several pre-implant surgical procedures are available in the case of tooth extraction for maintaining an excellent quantity of mucosa and for avoiding soft tissue collapse. During the healing process following the tooth extraction, the edentulous site undergoes a remarkable change; the walls of the socket reduce and the change in the buccal wall is more emphasized than its lingual/palatal counterpart. Moreover, the space previously occupied by the tooth root and the periodontal ligament is replaced mainly by bone marrow. Several graft materials including autogenous, allogenous, xenogeneic and alloplastic bone graft have been used to preserve the alveolar ridge following tooth extraction. However, as yet there is no material which can guarantee the preservation of the socket after teeth extraction [3, 4, 13-15].

Some clinicians have also suggested several surgical techniques to avoid hard and soft tissue resorption after tooth extraction. The placement of a bone substitute into the alveolar post-extraction socket with free gingival graft covering techniques may be consider a good therapeutic option for maintaining the alveolar bone volume. However, a systematic literature review on this topic, confirms how the free 


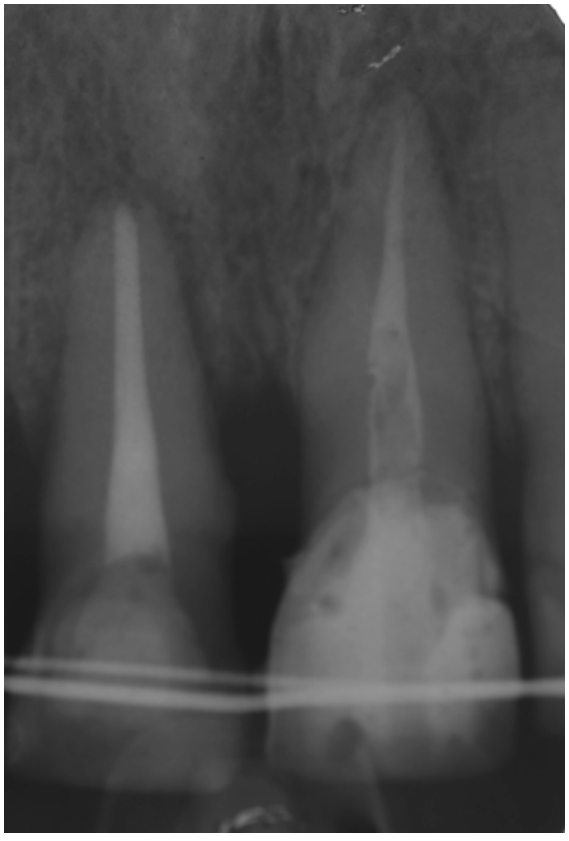

Fig. (1). Preoperative OPT shows the bone loss around the two upper incisors.

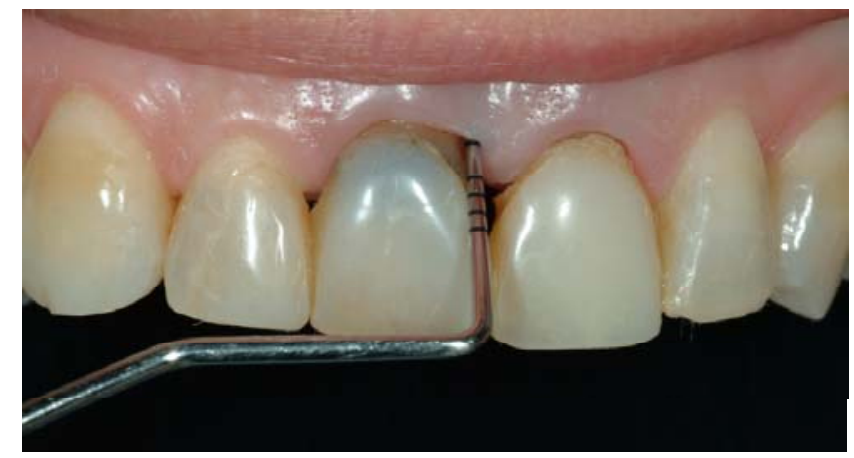

Fig. (2). Clinical examination underlines the upper incisors affected by periodontal disease.

graft positioning into the alveolar socket without a bone substitute cannot be considered a predictable technique for favouring the organization of the clot [16-19].

The vertical bone augmentation topic has been much debated in the recent literature and clinicians are still looking for a reliable, safe and predictable technique in order to get improved clinical success with resorbed ridges.

The slow orthodontic extrusion technique, to obtain a good amount of hard and soft tissue before dental implant placement, may be of interest to clinicians with a lot of expertise in orthodontic treatment but with little experience in surgical techniques. This technique avoids the surgical steps of the bone regeneration technique, and is more simply managed by the clinicians. However, this technique requires more time to see the final results compared with surgical guided bone regeneration (GBR). Long-term clinical prospective studies have shown that, in general, 5 weeks are needed to achieve 2-3 mm of extrusion, followed by a retention period of 8-10 weeks. [19, 20] Orthodontic extrusion for bone regeneration is a non traumatic technique whereas GBR is usually associated with pain and swelling in the immediate post op period [21].

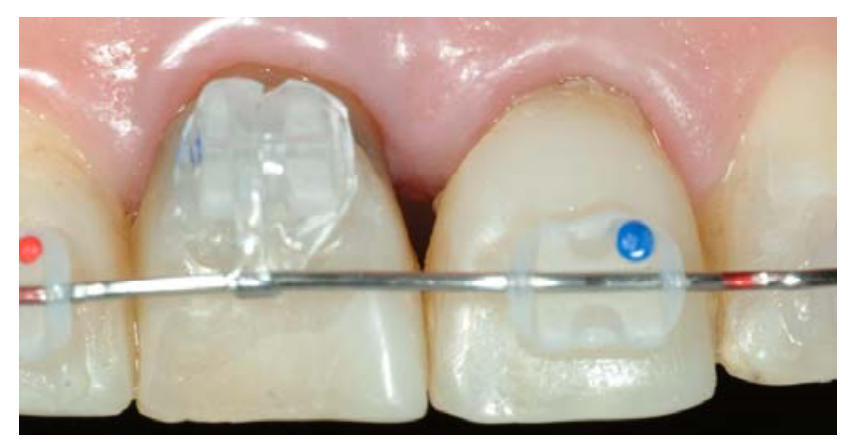

Fig. (3). Orthodontic brackets is apically positioned for performing extrusion.

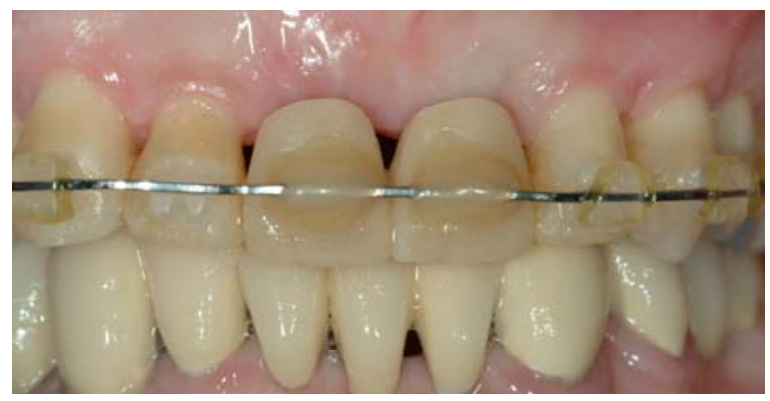

Fig. (4). Orthodontic treatment at the first stage.

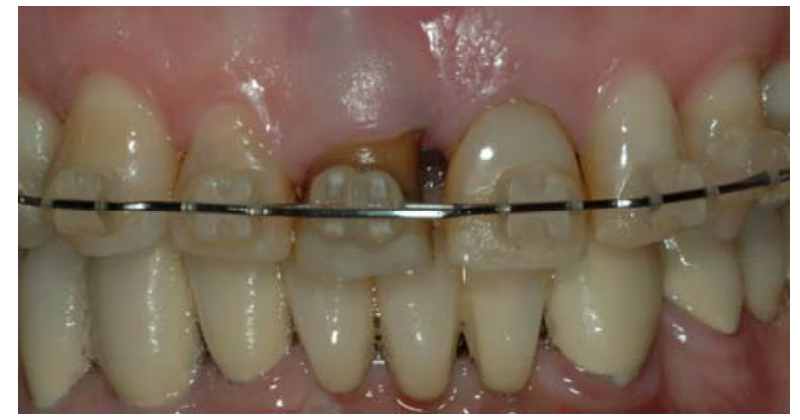

Fig. (5). Orthodontic extrusion is realized after three months of force application.

The aim of this report is to suggest how a combined surgical-periodontal and orthodontic technique could be applied by clinicians in order to solve bone defects problems in the aesthetic area.

\section{CASE HISTORY}

A 42 years old woman was referred to the Implantology Department of the University of Milan to have an evaluation of the upper incisors and a consequent aesthetic rehabilitation of this area. The clinical examination revealed the presence of periodontal disease of the upper incisors with severe mobility (Figs. 1, 2). A treatment plan involving tooth extractions, fresh socket preservation by a free graft (harvested from the palate and inserted in a tunnel created under the papillae), bone reconstruction and dental implants placement was proposed by the surgical team. Before tooth extraction, the surgical team decided on a slow orthodontic extrusion of the residual frontal upper incisors in order to increase the vertical dimension of the bone. For this reason, the two incisors underwent conservative treatment to gain adequate surface dimension in order to apply the orthodontic brackets (Figs. 3-5). Slow orthodontic treatment (upper frontal inci- 


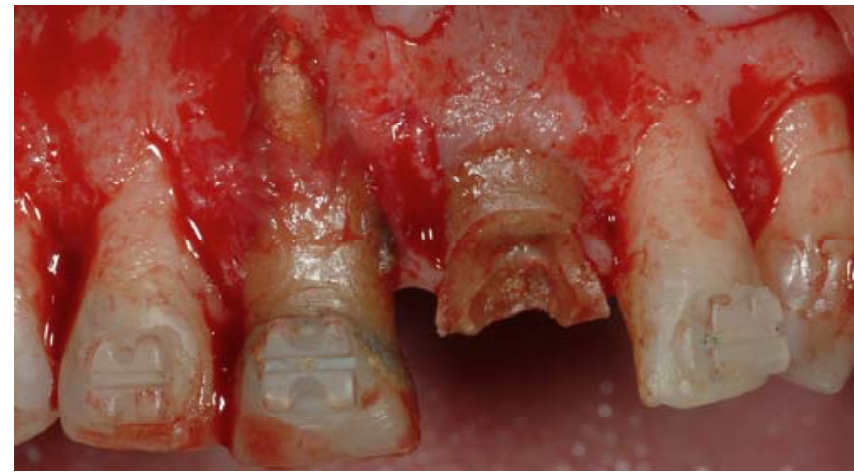

Fig. (6). A muco-periostal flap is elevated and the extraction of the two incisors is performed.

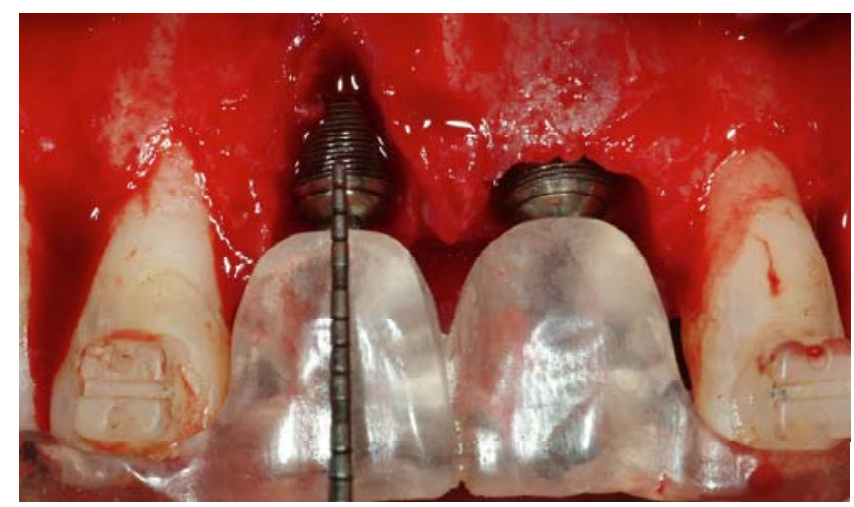

Fig. (7). Two dental implants are prosthetically positioned in the place of the central upper incisors.

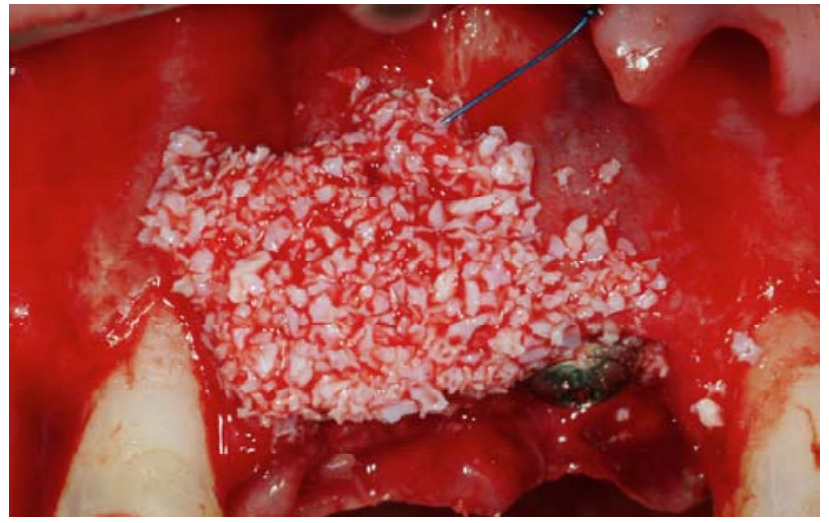

Fig. (8). Horizontal bone regeneration by application of bovine bone is performed.

sors extrusion) was performed over a period of 3 months, and surgical extraction of two teeth with positioning of two dental implants was then performed.

The patient started an antimicrobial therapy 1 day prior to surgery with $1,000 \mathrm{mg}$ amoxicillin $\left(\right.$ Zimox ${ }^{\circledR}$ PFIZER ITALIA) twice a day and she continued for more than 3 days post operatively

The presence of an adequate volume of hard and soft tissue is usually required to simplify the regenerative techniques. If a simple extraction is performed without graft positioning, it creates a collapse of the tissue causing a lack of available soft tissue. After local anaesthesia induction, a mucoperiostal flap was elevated with an incision made in the middle of the crest between the upper canines.

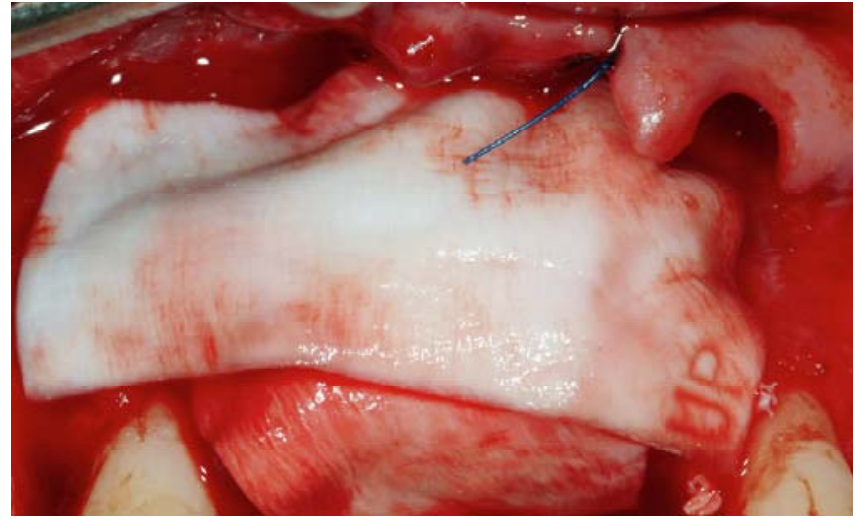

Fig. (9). Two collagen membranes are positioned to protect the bone graft.

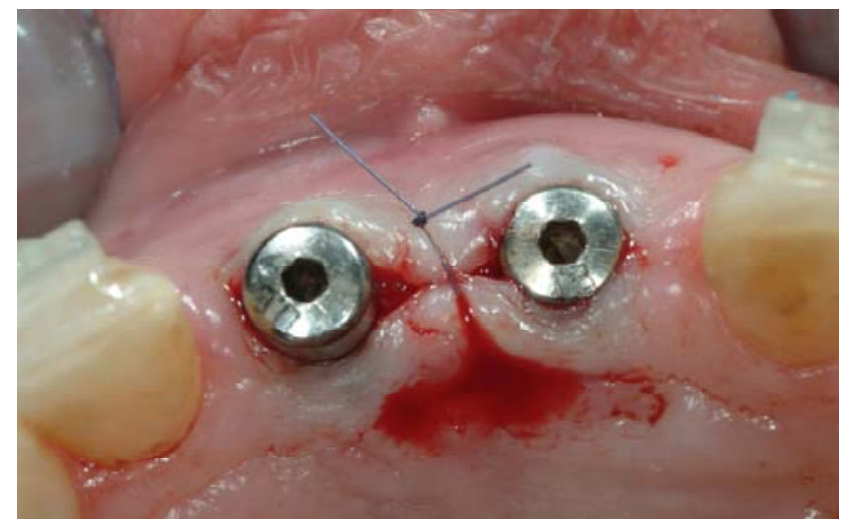

Fig. (10). The healing at the time of the suture removal confirms healthy condition of soft tissues.

The extraction of the two central upper incisors was then performed and two Astra ${ }^{\circledR}$ dental implants were positioned following a prosthetic guide (Figs. 6-9). The surgical area was irrigated with saline solution and bovine deproteinized bone (Bio-Oss Geistlich $\mathrm{CH}^{\circledR}$ ) was used for ridge reconstruction. Two resorbable membranes were positioned on the bone grafts. After suture application, two provisional crowns were then connected to the orthodontic wire for aesthetic provisional restoration. Post surgical analgesic treatment was performed by $100 \mathrm{mg}$ Nimesulide (Aulin ${ }^{\circledR}$, Roche $\mathrm{CH}$ ) administration twice a day for 5 days and the sutures were removed 14 days later.

This particular technique was performed in order to horizontally increase the residual ridge after central incisors extraction, to promote clot preservation, and obtain better healing of the bone wound. Simple 4-0 absorbable and 5-0 nonresorbable sutures were used to stabilise the position of the graft and to facilitate post-operative healing.

At the second week follow-up, the sutures were removed. The three week clinical control showed that soft tissues healing was uneventful (Figs. 10, 11).

Soft tissue healing at 14 days was within normal limits and no infection was revealed in the area and provisional resin crowns were again positioned. After three months, an OPT investigation was performed to underline dental implants osteointegration. At this time, the quantity of buccal keratinized mucosa was still insufficient and during the healing screw positioning, a connective tissue periosteal flap was 


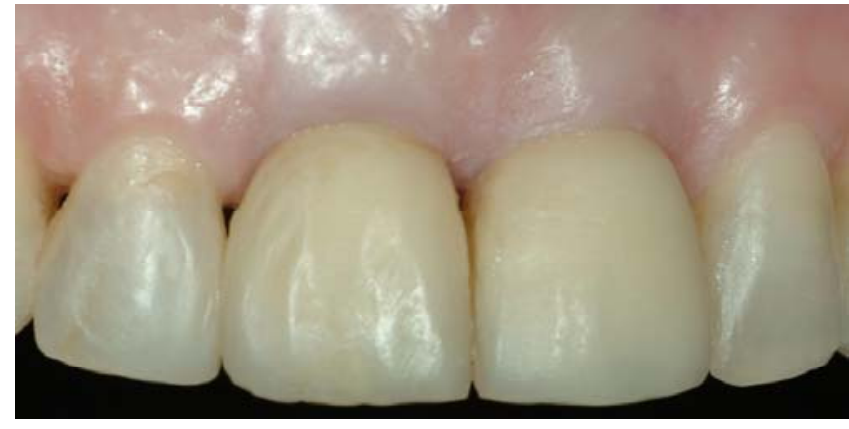

Fig. (11). Provisional crowns are positioned after 3 months for improving the soft tissue healing.

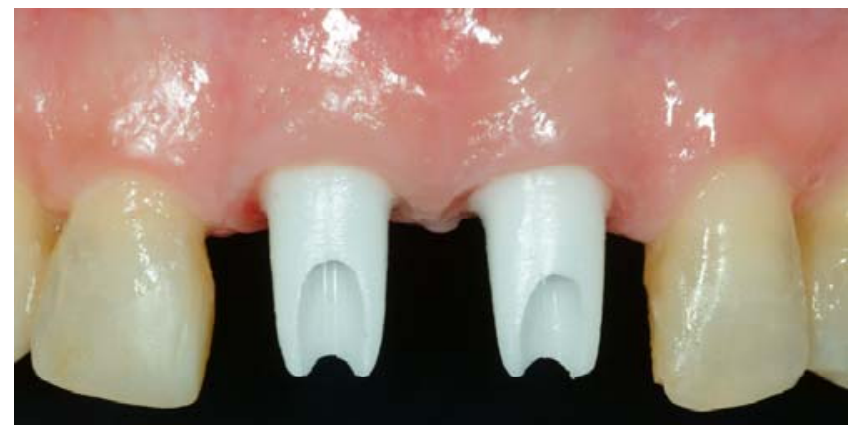

Fig. (12). Final zirconia abutments are positioned for maintaining high aesthetics.

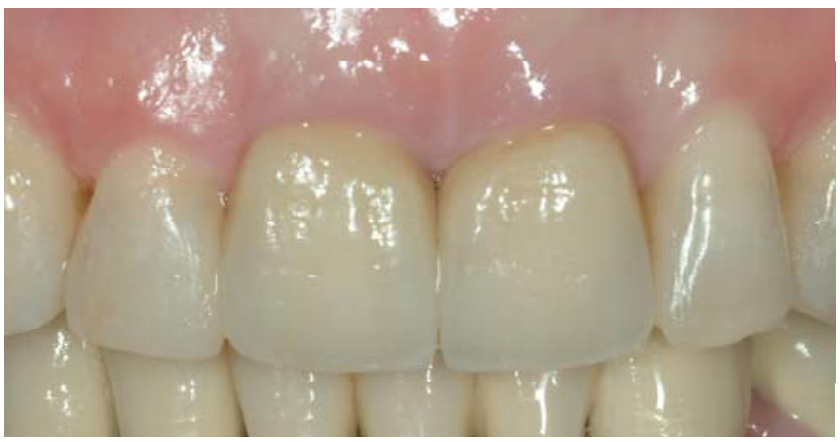

Fig. (13). Final ceramic crowns are positioned after 4 months.

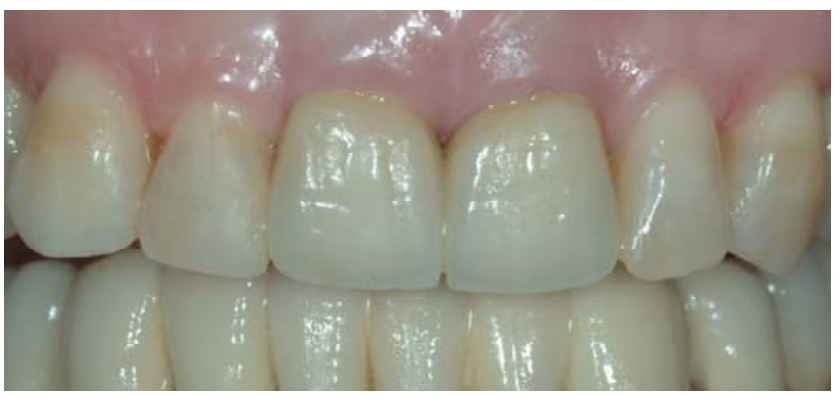

Fig. (14). The crowns at 24 months follow up control show good aesthetics and function results.

elevated from the palate and buccally positioned; transfers were then placed over the implants in order to get correct positioning. Four weeks later, provisional prosthetic crowns were placed for better soft tissue conditioning over the definitive abutments (Fig. 12). About 12 months after tooth extraction, the removal of the provisional prosthesis revealed excellent soft tissue healing. A mucogingival surgery was performed on the buccal surface to reduce excess tissue bulk

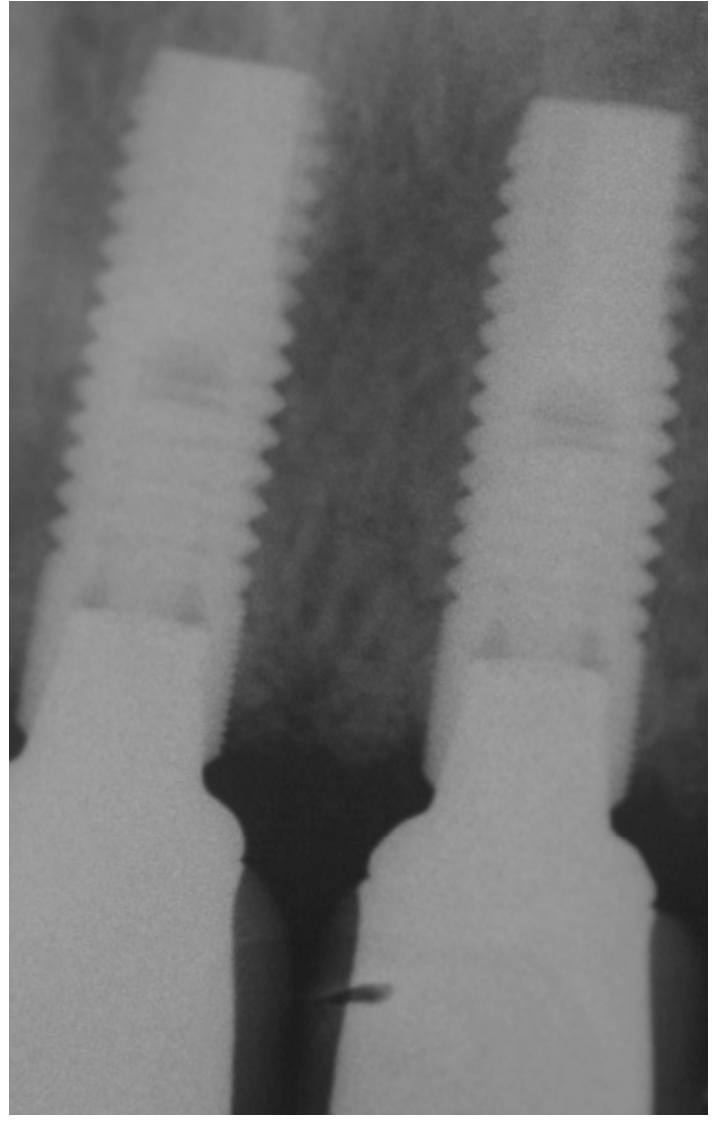

Fig. (15). The endoral radiographic investigation at 24 months follow up shows good integration of the dental implants placed.

and the final ceramic crowns were then cemented in. At 24 months after extraction, the patient showed a good amount of keratinized mucosa and the radiographic investigation revealed osseointegration of the dental implants (Figs. 13-15).

\section{DISCUSSION}

The technique used in the described clinical case took into account concept guidelines, published in study results at the end of 1980s, regarding mucogingival surgery and the orthodontic therapy. In these clinical studies some techniques of soft tissue thickness augmentation and root coverage with tissue graft harvested from the palate were described. Moreover, the combination of several techniques to increase the vertical component of the bone seems to be the main focus in recent years [20, 22-24].

Pre-prosthetic augmentation procedures, including alveolar ridge augmentation, using bone grafts are commonplace. Osteogenesis distraction and extra oral graft are usually selected for atrophic ridge augmentation. Small, space maintaining or horizontal bone defects can be treated with a combination of synthetic biomaterial or animal derivate material. The reported case underlines how the orthodontic movement may be used to treat vertical bone defects obtaining final excellent results using the GBR techniques.

According to Rasner, orthodontic extrusion of non- restorable teeth prior to implant placement appears to be a viable alternative to conventional surgical augmentative procedures in implant site development $[25,27]$. 
In contrast, the literature justifies the use of bone grafting materials in freshly extracted sockets to avoid hard and soft tissue resorption. When demineralized, freeze-dried bone allograft (DFDBA) was used in conjunction with a collagen membrane, the data of the analysed study showed how the width of the alveolar ridge did not decrease significantly, while the width of the socket sites, which healed naturally, showed more evidence of a significance decrease..

Other studies demonstrated how, even with no barrier membranes, a socket fill of nearly $85 \%$ could be achieved by placing porous bovine bone mineral in fresh extraction sites $[19,20]$.

However, the application in the fresh socket of deproteinized bovine bone or collagen bovine seems to have the potential of limiting but not avoiding post-operative contour shrinkage [18, 19, 20, 26, 28].

Several animal study and in vitro investigations have been performed to find a reliable technique for a better socket preservation after tooth extraction. On this topic, many authors have concluded that socket preservation techniques, were not able to entirely compensate the alterations after tooth extraction. Yet, incorporation of synthetic bone or collagen seems to have the potential to reduce post-operative hard and soft tissues modifications [27-29]. However, other studies have underlined how the alveolar bone resorption, following tooth extraction, is an common event because there are no predictable and available techniques to avoid this process. For this reason, the best way to preserve the alveolar bone is related to the correct procedure in performing tooth extraction [30-33].

To obtain the best result in the socket preservation, a wide range of barrier membranes have been used in numerous studies over the years such as expanded poly- tetrafluoroethylene (ePTFE), collagen, polyglycolic acid and polyglactin $[9,10]$. These can be grouped into 2 major categories: non resorbable and resorbable membranes. However, the resorption time of the resorbable membranes is different for each brand used. If clinicians know the chemical characteristic of the material used and therefore the bone healing time, this will favour excellent augmented bone at the time of dental implant positioning [33-38].

This report clearly points out how the combination of different, predictable and safe techniques can be used with the aim of achieving both function and pleasing aesthetics results for the patients. Diverse treatments are available to the clinician so the choice made should be based on defects size, time of procedure, and the patient's aesthetics requests $[39,40]$.

\section{CONCLUSION}

Dimensional changes after tooth extraction often result in bone resorption which complicates restorations with implants or traditional prostheses. Preservation of the alveolar dimensions after tooth extraction is crucial to achieve optimal aesthetic and functional prosthodontics results. In addition, with the high usage of dental implants in replacing nonrestorable teeth, the preservation of the existing alveolus is essential to maintain adequate bone volume for placement and stabilization of the implants. Non traumatic extraction and socket preservation techniques have been introduced to minimize bone resorption after tooth extraction. Several hard and soft tissue management surgical techniques are available today to assist the clinician in achieving an ideal aesthetic treatment result. Maintenance of an extraction socket for future implant therapy does not exclude immediate implant placement, but knowledge and experience are needed to determine the best treatment modality.

The reported case shows a successfully management of the upper incisor area in which non recoverable teeth have been replaced by dental implants. Predictable therapeutic steps for obtaining effective aesthetic and long-term results are related to a multidisciplinary approach to the procedure. The application of the slow orthodontic extrusion technique is helpful in increasing the vertical height of the bony tissue.

\section{CONFLICT OF INTEREST}

The authors confirm that this article content has no conflicts of interest.

\section{ACKNOWLEDGEMENT}

None declared.

\section{KEY MESSAGE}

Orthodontic slow extrusion of the teeth may be considered a valuable therapeutic option to increase the quality and the quantity of hard and soft tissue before dental implant positioning. Clinicians and periodontist should consider a multidisciplinary approach in order to obtain high aesthetic results.

\section{REFERENCES}

[1] Bianchi AE, Sanfilippo F. Single-tooth replacement by immediate implant and connective tissue graft: a 1-9-year clinical evaluation. Clin Oral Implants Res 2004; 15(3): 269-77.

[2] Carlsson GE, Ragnarson N, Astrand P. Changes in height of the alveolar process in edentulous segments: a longitudinal clinical and radiographic study of full upper denture cases with residual lower anteriors. Odontol Tidskr 1967; 75(3):193-208. (No abstract available).

[3] Araújo MG, Sukekava F, Wennström JL, Lindhe J. Ridge alterations following implant placement in fresh extraction sockets: an experimental study in the dog. J Clin Periodontol 2005; 32(6): 64552.

[4] Araújo MG, Lindhe J. Dimensional ridge alterations following tooth extraction: an experimental study in the dog. J Clin Periodontol 2005; 32(2): 212-8.

[5] Tallgren A. The continuing reduction of the residual alveolar ridges in complete denture wearers: a mixed-longitudinal study covering 25 years. J Prosthet Dent 1972; 27(2):120-32.

[6] Misch CE. Dental education-meeting the demands of implant dentistry. J Am Dent Assoc 1990; 121(3): 334, 336, 338.

[7] Landsberg CJ. Implementing socket seal surgery as a socket preservation technique for pontic site development: surgical steps revisited: a report of two cases. J Periodontol 2008; 79(5): 945-54.

[8] John V, De Poi R, Blanchard S. Socket preservation as a precursor of future implant placement: review of the literature and case reports. Compend Contin Educ Dent 2007; 28(12): 646-53; quiz 654, 671. Review.

[9] Keith JD Jr, Salama MA. Ridge preservation and augmentation using regenerative materials to enhance implant predictability and esthetics. Compend Contin Educ Dent 2007; 28(11): 614-21.

[10] Oltramari PV, Navarro RL, Henriques JF, et al. Evaluation of bone height and bone density after tooth extraction: an experimental study in minipigs. Oral Surg Oral Med Oral Pathol Oral Radiol Endod 2007; 104(5): e9-16.

[11] Shi B, Zhou Y, Wang YN, Cheng XR. Alveolar ridge preservation prior to implant placement with surgical-grade calcium sulfate and 
platelet-rich plasma: a pilot study in a canine model. Int J Oral Maxillofac Implants 2007; 22(4): 656-65.

[12] Irinakis T, Tabesh M. Preserving the socket dimensions with bone grafting in single sites: an esthetic surgical approach when planning delayed implant placement. J Oral Implantol 2007; 33(3):156-63.

[13] Cobankara FK, Ungor M. Replantation after extended dry storage of avulsed permanent incisors: report of a case. Dent Traumatol 2007; 23(4): 251-6.

[14] Babbush CA. A new atraumatic system for tooth removal and immediate implant restoration. Implant Dent 2007; 16(2):139-45.

[15] Rothamel D, Schwarz F, Herten M, et al. Dimensional ridge alterations following tooth extraction: an experimental study in the dog. Mund Kiefer Gesichtschir 2007; 11(2): 89-97.

[16] Irinakis T. Rationale for socket preservation after extraction of a single-rooted tooth when planning for future implant placement. J Can Dent Assoc 2006; 72(10): 917-22.

[17] Hong HH, Tsai AI, Liang CH, et al. Preserving pulpal health of a geminated maxillary lateral incisor through multidisciplinary care. Int Endod J 2006; 39(9): 730-7.

[18] Fowler EB, Breault LG, Rebitski G. Ridge preservation utilizing an acellular dermal allograft and demineralized freeze-dried bone allograft: Part II. Immediate endosseous implant placement. J Periodontol 2000; 71(8):1360-4. Erratum in: J Periodontol 2000; 71(10): 1670.

[19] Fowler EB, Breault LG, Rebitski G. Ridge preservation utilizing an acellular dermal allograft and demineralized freeze-dried bone allograft: Part I: a report of 2 cases. J Periodontol 2000; 71(8):13539.

[20] Langer B. Calagna L. Subephitelial connective tissue graft: a new approach to the enhancement of anterior cosmetics. Int J Periodont Rest Dent 1982; 2: 23 .

[21] Urban IA, Jovanovic SA, Lozada JL. Vertical ridge augmentation using guided bone regeneration (GBR) in three clinical scenarios prior to implant placement: a retrospective study of 35 patients 12 to 72 months after loading. Int J Oral Maxillofac Implants 2009; 24(3): 502-10.

[22] Rosenberg E, Garber DA, Malinowski A. Considerations in the utilization of the free gingival graft. Quintes Int Dent Dig 1981; 12(9): 927-32.

[23] Caffesse RG, Espinel MC. Lateral sliding flap with a free gingival graft technique in the treatment of localized gingival recessions. Int J Periodont Rest Dent 1981; 1(6): 22-9.

[24] Matter J. Free gingival grafts for the treatment of gingival recession: a review of some techniques. J Clin Periodontol 1982; 9(2): 103-14.

[25] Rasner SL. Orthodontic extrusion: an adjunct to implant treatment. Dent Today 2011; 30(3):104, 106,108-9.

[26] Artzi Z, Tal H, Dayan D. Porous bovine bone mineral in healing of human extraction sockets. Part 1: histomorphometric evaluations at 9 months. J Periodontol 2000; 71(6): 1015-23.
[27] Borio EA. Orthodontic extrusion and implant restoration to manage localized advanced bone loss: a clinical case review. Compend Contin Educ Dent 2011; 32(6): 50-5.

[28] Fickl S, Zuhr O, Wachtel H, Stappert CF, Stein JM, Hürzeler MB. Dimensional changes of the alveolar ridge contour after different socket preservation techniques. J Clin Periodontol 2008; 35(10): 906-13. [Epub 2008 Aug 17].

[29] Cornelini R, Scarano A, Covani U, Petrone G, Piattelli A. Immediate one-stage postextraction implant: a human clinical and histologic case report. Int J Oral Maxillofac Implants 2000; 15(3): 432-7.

[30] Nemcovsky CE, Moses O. Rotated palatal flap: a surgical approach to increase keratinized tissue width in maxillary implant uncovering: technique and clinical evaluation (12-2002). Int J Periodont Rest Dent 2002; 22(6): 607-12.

[31] Scharf DR, Tarnow DP. Modified roll technique for localized alveolar ridge Augmentation. Int J Periodont Rest Dent 1992; 12(5): 415-25.

[32] Nemocovsky CE, Artzi Z. Split palatal flap: a surgical approach for maxillary implant uncovering in caseswith reduced keratinized tissue: technique and clinical result. Int J Periodont Rest Dent 1999; 19(4): 385-93.

[33] Servor J. The use of free gingival grafts to improve the implant soft tissue interface: rationale and technique. Pract Periodont Aesthet Dent 1992; 4: 59.

[34] Kinsel RP, Lamb RE. Development of gingival esthetic in the edentulous patient prior to dental implant placment using a flangeless removable prosthesis: a case report. Int J Oral Maxillofac Implant 2002; 17: 866-72.

[35] Orsini G, Murmura G, Artese L, Piattelli A, Piccirilli M, Caputi S. Tissue healing under provisional restorations with ovate pontics: a pilot human histological study. J Prosthet Dent 2006; 96(4): 252-7.

[36] Jung RE, Siegenthaler DW, Hammerle CH Postextraction tissue management: a soft tissue punch technique. Int J Periodont Rest Dent 2004; 24(6): 545-53.

[37] Bartee BK. Extraction site reconstruction for alveolar ridge preservation. Part 2: membrane-assisted surgical technique. J Oral Implantol 2001; 27(4):194-7.

[38] Carmagnola D, Adriaens P, Berglundh T. Healing of human extraction sockets filled with Bio-Oss. Clin Oral Implants Res 2003; 14(2):137-43.

[39] Iasella JM, Greenwell H, Miller RL, et al. Ridge preservation with freeze-dried bone allograft and a collagen membrane compared to extraction alone for implant site development: a clinical and histologic study in humans. J Periodontol 2003; 74(7): 990-9.

[40] Artzi Z, Tal H, Dayan D. Porous bovine bone mineral in healing of human extraction sockets. Part 1: histomorphometric evaluations at 9 months. J Periodontol 2000; 71(6):1015-23.

\begin{tabular}{lll}
\hline Received: June 15, 2012 & Revised: July 29, 2012 & Accepted: August 02, 2012
\end{tabular}

(C) Maiorana et al.; Licensee Bentham Open.

This is an open access article licensed under the terms of the Creative Commons Attribution Non-Commercial License (http://creativecommons.org/licenses/by-nc/3.0/) which permits unrestricted, non-commercial use, distribution and reproduction in any medium, provided the work is properly cited. 